\title{
SINKRONISASI REFORMULASI SISTEM PERENCANAAN PEMBANGUNAN NASIONAL MODEL GBHN DENGAN SISTEM PRESIDENSIAL
}

\author{
Oleh : Novira Maharani Sukma, S.H., M.H. *
}

\begin{abstract}
This paper discusses the MPR discourse to support the existence of GBHN as the direction of national development in the Indonesian state administration system, it is necessary only here, it is merely to determine the direction of Indonesia's national development to become more focused and consistent in accordance with the presidential system adopted by Indonesia This does not necessarily change the position of being the highest institution of the state anymore as it was in practice before the amendments to the 1945 Constitution.

Efforts to bring GBHN back into the presidential system in Indonesia should not only give the impression of changing its name from RPJPN to the new model GBHN. With the MPR TAP form, the new GBHN will be a control tool for measuring the success rate and accuracy of medium-term development planning (RPJPMN) that is shaped in the product of the Act. The MPR MP is theoretically a staatsgerundgezets (basic rules of the state) Act, but the position is level under the 1945 Constitution of the Republic of Indonesia.
\end{abstract}

Keywords: GBHN, Presidential System, Development Planning

\section{ABSTRAK}

Tulisan ini membahas wacana MPR untuk mengembalikan adanya GBHN sebagai arah pembangunan nasional dalam sistem ketatanegaraan Indonesia, perlu diperhatikan disini bahwa, hal ini hanya semata-mata untuk menentukan arah pembangunan nasional Indonesia agar menjadi lebih terarah dan konsisten yang tetap sesuai dengan kerangka sistem Presidensial yang dianut oleh Indonesia. Hal ini tidak serta merta mengubah kedudukan menjadi lembaga tertinggi negara lagi seperti dalam prakteknya sebelum amandemen UUD Tahun 1945.

Upaya memunculkan kembali GBHN dalam sistem presidensial di Indonesia , jangan sampai hanya menimbulkan kesan mengganti nama saja dari RPJPN ke GBHN model yang baru. Dengan bentuk TAP MPR, GBHN yang baru akan menjadi alat kendali untuk mengukur tingkat keberhasilan dan ketepatan perencanaan pembangunan jangka menengah (RPJPMN) yang diberi bentuk dalam produk Undang-Undang.TAP MPR secara teoritik merupakan staatsgerundgezets (aturan dasar bernegara), sama seperti Undang-Undang, namun kedudukannya setingkat dibawah UUD NRI Tahun 1945.

Kata Kunci : GBHN, Sistem Presidensial, Perencanaan Pembangunan.

\footnotetext{
*Dosen Fakultas Hukum Universitas Diponegoro Semarang
} 


\section{PENDAHULUAN}

Salah satu perubahan yang penting dalam amandemen UUD 1945 adalah tidak adanya Garis-Garis Besar Haluan Negara (GBHN) sebagai arah pembangunan nasional dalam sistem ketatanegaraan Indonesia. Arah pembangunan bangsa saat ini, terutama arah pembangunan nasional seakan kurang fokus, tidak terarah dan sulit diukur tingkat keberhasilannya.Hal ini memicu adanya gagasan untuk kembali menghadirkan GBHN. Tapi keinginan itu menimbulkan berbagai kontroversi.

GBHN adalah merupakan haluan negara tentang penyelenggaraan negara dalam garis-garis besar sebagai pernyataan kehendak rakyat secara menyeluruh dan terpadu. Sebagai haluan negara, maka tentu dapat dipahami bahwa keberadaan GBHN itu sendiri dalam pelaksanaan roda pemerintahan sangatlah dibutuhkan. Melalui GBHN, maka arah dan tujuan perjalanan roda pemerintahan akan dapat lebih mudah dipahami sehingga cukup memudahkan dalam mengoreksi tingkat keberhasilan dan pencapaian yang dilaksanakan oleh suatu pemerintahan yang sedang berkuasa.

Majelis Permusyawaratan Rakyat (MPR) adalah salah satu lembaga yang mengalami perubahan mendasar dalam hal kedudukan, fungsi dan perannya pasca amandemen UUD 1945. Sebelum amandemen, MPR merupakan lembaga tertinggi Negara dengan kewenangannya menetapkan Undang-Undang Dasar dan Garis-Garis Besar Haluan Negara (GBHN) serta memilih dan mengangkat Presiden dan Wakil Presiden. Setelah amandemen, kedudukan MPR tidak lagi menjadi lembaga tertinggi Negara, tetapi berkedudukan sejajar dengan lembagalembaga Negara lainnya yaitu sebagai lembaga Negara, dan fungsinya terbatas pada satu kewenangan rutin yaitu melantik Presiden dan Wakil Presiden terpilih hasil pemilihan umum, selebihnya merupakan kewenangan insidental MPR, seperti memberhentikan Presiden dan/atau Wakil Presiden dalam masa jabatannya menurut Undang-Undang Dasar, mengubah dan menetapkan Undang-Undang Dasar serta kewenangan insidental lain sebagaimana dimaksud dalam Pasal 8 ayat (2) dan ayat (3) UUD NRI Tahun 1945.

Perubahan mendasar lainnya menyangkut keberadaan GBHN. Pada masa Orde Baru, GBHN merupakan pedoman atau acuan bagi Presiden dalam menjalankan roda pemerintahan. Jika Presiden tidak mengikuti atau melanggar apa yang sudah ditetapkan dalam GBHN, maka MPR dapat memberhentikan 
Presiden. Namun, sejak era reformasi, eksistensi GBHN sudah tidak ada lagi sebagai konsekuensi adanya amandemen UUD Tahun 1945. Hilangnya GBHN telah mengakibatkan hilangnya sarana pemandu pelaksanaan pembangunan nasional yang telah terbukti mampu memandu pemerintahan orde baru dalam melaksanakan kegiatan pembangunan berturut-turut sejak tahun 1973-1998 (Cholid Mahmud, 2012 : 1).

Sebagai gantinya, pedoman penyelenggaraan pembangunan adalah Rencana Pembangunan Jangka Panjang Nasional (RPJPN) selama 20 tahun sebagaimana dituangkan dalam UU Nomor 17 Tahun 2007, sebagai amanat dari Pasal 13 ayat (1) UU No 25 Tahun 2004 tentang Sistem Perencanaan Pembangunan Nasional (SPPN). Dari segi nomenklatur, penamaan antara GBHN dengan kedua UU tersebut merupakan dua hal yang berbeda. Tetapi jika dilihat dari segi isi materi muatan antara UU dan GBHN, substansi yang terkandung antara keduanya berbeda. GBHN sebagai sistem perencanaan pembangunan merupakan keputusan bersama dan lebih merupakan penjabaran dari tujuan negara yang hendak dicapai. Sementara itu RPJPN adalah sistem perencanaan pembagunan nasional yang dibuat oleh pemerintah (eksekutif) dan cenderung merupakan penjabaran visi dan misi presiden yang sedang memerintah.

Namun harus diakui bahwa RPJPN belum mampu dibangun sebagai konsepsi yang lebih operasional agar tujuan dan proses pembangunan tidak terombang-ambing oleh tarik menarik kepentingan dari berbagai pihak. Disinilah keberadaan RPJPN belum mampu mengimbangi atau menggantikan keberadaan GBHN sebagai penunjuk arah maupun kompas bagi perjalanan Bangsa Indonesia ke depan. Bahkan salah satu alasan sejumlah pihak yang pro terhadap upaya menghidupkan kembali GBHN didasarkan fakta yang diperoleh di lapangan yang menunjukkan bahwa baik Rencana Pembangunan Jangka Menengah (RPJM) maupun RPJP tidak mampu memberikan solusi untuk menyatukan visi pembangunan di seluruh tingkatan dalam rangka menciptakan kesejahteraan masyarakat (Robinson Sembiring, 2011).

Ketika GBHN dihapuskan dari sistem ketatanegaraan Indonesia, sulit untuk mengukur tingkat keberhasilan suatu pemerintahan yang dijalankan. Karena tidak ditemukan hal apa saja yang menjadi ukuran maupun kriteria keberhasilan terhadap suatu pemerintahan secara nyata. Hapusnya keberadaan 
GBHN hanyalah sebagai konsekuensi dari upaya pengurangan kewenangan MPR yang sebelumnya ditempatkan sebagai lembaga tertinggi negara. Hal itu menunjukkan bahwa penghapusan GBHN tidaklah dilatarbelakangi atas suatu persoalan yang mengarah pada keberadaan GBHN itu sendiri. Apalagi kemudian bila dikaitkan dengan fakta historisnya bahwa sejak GBHN dikenal di tanah air, belum ditemukan sejumlah persoalan yang menunjukkan bahwa keberadaan GBHN itu sendiri telah membawa persoalan bagi eksistensi Bangsa Indonesia (Janpatar Simamora, 2016: 7). Seandainya GBHN masih berlaku, maka tentunya dapat dipastikan bahwa baik presiden, gubernur maupun bupati dan wali kota akan membentuk RPJMN dan RPJMD yang mengacu pada GBHN sebagai haluan negara.

Berdasarkan Undang-Undang Nomor 25 Tahun 2004 Tentang Sistem Perencanaan Pembangunan Nasional, pengertian perencanaan pembangunan adalah ujung tombak manajemen dalam mengelola pembangunan di suatu negara terkait dalam menentukan tindakan yang akurat dan tepat di masa depan melalui urutan skala prioritas dengan memperhitungkan sumber daya yang tersedia.Selain hal tersebut, tanpa adanya pedoman pembangunan yang terarah tidak mungkin tujuan negara yang tertuang pada alinea ke-4 Pembukaan UUD NRI Tahun 1945 dapat tercapai. Mengingat pentingnya arti pembangunan, maka diperlukan suatu sistem perencanaan pembangunan nasional yang tepat dan sesuai dengan kebutuhan bangsa Indonesia saat ini.

\section{PEMBAHASAN}

Pada masa Orde Baru, GBHN merupakan pedoman bagi Presiden dalam menjalankan roda pemerintahan. Jika Presiden tidak mengikuti atau melanggar apa yang sudah ditetapkan dalam GBHN, maka MPR berdasarkan kewenangan yang diberikan oleh konstitusi, dapat memberhentikan Presiden dalam masa jabatannya. Maksud dan tujuan ditetapkannya Garis-Garis Besar Haluan Negara adalah dalam rangka memberikan arah penyelenggaraan negara dengan tujuan menwujudkan kehidupan yang demokratis, berkeadilan sosial, melindungi hak asasi manusia, menegakkan supremasi hukum dalam tatanan masyarakat dan bangsa yang beradab, berakhlak mulia, mandiri, bebas, maju dan sejahtera untuk kurun waktu lima tahun ke depan. Dalam pembentukan GBHN sejak awal dimaksudkan untuk memberikan arah yang jelas bagi penyelenggaraan 
kehidupan bangsa selama lima tahun ke depan. Dengan demikian, dapat dipahami bahwa GBHN menjadi penunjuk arah pembangunan bangsa sesuai dengan apa yang diinginkan oleh rakyat, khususnya keinginan para pihak yang berkompeten di dalam pembentukannya.

Semenjak era reformasi, eksistensi GBHN sudah tidak ada lagi, hal ini merupakan konsekuensi adanya amandemen Undang-Undang Dasar 1945 (UUD 1945). Konsekuensi lainnya adalah kedudukan MPR sudah tidak lagi menjadi lembaga tertinggi negara yang memiliki kewenangan diantaranya menetapkan GBHN, serta memilih dan mengangkat Presiden dan Wakil Presiden.Setelah tidak adanya lagi GBHN yang merupakan konsekuensi dari penghapusan kewenangan MPR dalam menetapkan GBHN, maka konsep pembangunan nasional dilegalisasikan melalui pembentukan Undang-Undang Nomor 25 Tahun 2004 Tentang Sistem Perencanaan Pembangunan Nasional (SPPN). Kemudian Undang-Undang ini mengamanatkan adanya suatu dokumen negara mengenai perencanaan jangka panjang bagi roda perjalanan pemerintahan di Indonesia. Dalam rangka memenuhi amanat Undang-Undang Nomor 25 Tahun 2004, maka lahirlah Undang-Undang Nomor 17 Tahun 2007 Tentang Rencana Pembangunan Jangka Panjang Nasional (RPJPN). RPJPN ini menjadi rujukan pembangunan lima tahunan yang disebut dengan Rencana Pembangunan Jangka Menengah Nasional (RPJMN): RPJMN I Tahun 20052009, RPJMN II Tahun 2010-2014, RPJMN III Tahun 2015-2019, dan RPJMN IV Tahun 2020-2024.

Namun dalam prakteknya, pelaksanaan RPJPMN dan RPJPN tidak sesuai dengan apa yang telah direncanakan. RPJPMN danRPJPN hanya sekedar formalitas saja karena ini adalah implementasi dari visi misi dari presiden yang terpilih, karena Presidenlah yang menentukan sendiri tanpa harus mendapat persetujuan dari DPR, DPD, bahkan MPR. Selain itu, RPJPN dan RPJPMN juga tidak mengikat dan tidak mengatur lembaga-lembaga negara lainnya kecuali Presiden, seperti DPR, DPD, MA, MK, BPK, KY dan lainnya. Sejumlah kalangan menilai bahwa RPJPMN kurang mampu menjawab persoalan yang dihadapi oleh negara, apalagi jika dikaitkan dengan konteks kesinambungan antar-periode pemerintahan presiden terpilih dan sinerginya dengan perencanaan pembangunan di daerah yang ditentukan oleh Kepala Daerah. 
Sejumlah catatan permasalahan yang berkaitan dengan sistem perencanaan pembangunan pasca reformasi, diantaranya sebagai berikut (M. Taufiq, 2016, 3) :

a. Proses reformulasi RPJPN dan RPJPMN dinilai lemah, karena executive perspective.

b. Terdapat proses inkonsistensi dan diskontinuitas pelaksanaan RPJPN dan RPJPMN dikarenakan proses politik, yaitu proses pergantian presiden 5 tahun sekali.

c. RPJPMN masih kurang bisa sinkron dengan RPJMD yang ada di daerah. Orientasi RPJPM (baik yang ada di pusat dan di daerah) adalah refleksi dari visi misi politik pemimpin yang terpilih dalam proses pemilu, yang terkadang kenyataannya menunjukkan bahwa orientasi politik Presiden dengan orientasi Kepala Daerah berbeda. Dengan tidak adanya sinkronisasi mengenai perencanaan pembangunan Nasional dengan perencanaan pembangunan di daerah, maka berdampak pada tidak efektifnya perencanaan pembangunan mencapai tujuan negara yang ada di dalam Pembukaan UUD NRI Tahun 1945 pada alinea ke empat dan tidak efisiennya anggaran belanja negara.

GBHN merupakan sebuah sistem perencanaan pembangunan nasional yang lahir atas kesepakatan bersama sebagai penjabaran tujuan negara yang tertuang dalam pembukaan UUD Tahun 1945. Sedangkan RPJPN cenderung berupa perencanaan pembangunan nasional dari pemerintah yang sedang berkuasa, yang cenderung berubah seiring dengan pergantian pemerintahan. Suatu perencanaan pembangunan yang tidak konsisten dan mudah berubah dan berganti sulit untuk dapat mewujudkan tujuan negara sebagaimana yang diharapkan. Kenyataannya pada era reformasi, pembagunan yang dilakukan berdasarkan atas multi pemerintahanan. Setiap ganti pemerintahan ganti pula program pembagunannya. Sulitnya koordinasi pembagunan merupakan masalah yang dihadapi pemerintah dalam pelaksanaan pembagunan di bawah sistem RPJPN.

Dilihat berdasarkan sistem ketatanegaraan kita, SPPN sudah cukup ideal. Adopsi pendekatan politik, teknokratik, partisipatif dan perpaduan pendekatan top down dan bootom up, merupakan beberapa alasan kuat untuk mendukung argumenrtasi tersebut. Implikasinya, menjadikan SPPN merupakan sebuah 
sistem perencanaan pembangunan yang intergratif, yang menjanjikan keterpaduan proses pembangunan nasional, pembangunan daerah maupun pembangunan antar daerah, dengan melibatkan multi-stakeholder.

Ditemui kendala perencanaan dan penganggaran SPPN di lapangan. Kendala-kendala tersebut secara umum dapat dirumuskan dalam beberapa hal sebagai berikut (Andrial Putra, 2016: 5) :

1. Mulai tahap perencanaan, pelaksanaan, sampai pada tahap pengawasan ada di satu garis komando, yaitu Presiden. Sehingga tidak ada mekanisme check and balance dari SPPN tersebut. Presiden sendiri yang menentukan arah pembangunan nasional negara. Tidak ada pengawasan dari pihak lain, sehingga untuk menentukan keberhasilan dari SPPN ini tidak mudah.

2. Dalam SPPN terdapat mekanisme bernama Musrenbang atau Musyawarah Perencanaan Pembangunan yang terdiri dari unsur-unsur penyelenggara negara, akademisi dan unsur masyarakat (Hanif Nurcholis, 2009 : 97). Yang diharapkan bahwa SPPN itu dibuat berdasarkan kajian praktik dan akademik yang mumpuni karena melibatkan banyak pihak dalam perencanaanya. Namun sekali lagi, Musrenbang atau Musyawarah Perencanaan Pembangunan hanya bersifat formalitas saja, karena pada akhirnya perencanaan final atau akhir dari SPPN ada di tangan Presiden.

3. Lemahnya koordinasi dalam pengelolaan data dan informasi sehingga tidak tepat sasaran.

4. Lemahnya sistem pemantauan, evaluasi dan pengendalian (safeguarding).

5. Lemahnya koordinasi antara pemerintah pusat dan pemerintah daerah.

6. Tidak adanya jaminan kepastian bahwa apa yang telah dikontruksikan secara ideal dalam peraturan perundang-undangan SPPN maupun RPJPN tidak dilaksanakan secara konsisten oleh pemangku kepentingan terkait.

Dalam proses amandemen UUD 1945 sejak tahun 1999 hingga tahun 2002 terdapat lima komitmen yang disepakati oleh panitia ad-hoc MPR RI (Jazim Hamidi dan Mustafa Lutfi , 2010 : 148) Lima komitmen tersebut yakni tidak mengubah pembukaan UUD 1945, tetap mempertahankan NKRI, penjelasan UUD 1945 ditiadakan, perubahan UUD 1945 dilakukan dengan cara adendum, dan yang terakhir adalah mempertegas sistem pemerintahan presidensial (Ni'matul Huda, 2007 : 53).Kesepakatan dasar untuk mempertegas sistem pemerintahan presidensil dimaksudkan untuk memperkokoh sistem 
pemerintahan yang stabil dan demokratis yang dianut oleh negara Republik Indonesia agar sesuai dengan apa yang telah dipilih oleh founding fathers pada tahun 1945.

Berbicara dalam konteks sistem pemerintahan maka erat kaitannya dengan bagaimana cara pemerintahan di suatu negara dijalankan. Dalam sistem pemerintahan presidensil menurut Prof. Jimly, Abdul Ghoffar dan Duchacck terdapat beberapa karakteristik khusus yang membedakannya dengan sistem pemerintahan parlementer yakni : (1) Presiden dan kabinetnya tidak bertanggungjawab kepada legislatif, akan tetapi langsung kepada rakyat (Abdul Ghoffar, 2009 : 49). (2) Presiden memiliki hak prerogratif untuk menentuhkan arah pembangunan nasional selaku kepala pemerintahan sekaligus kepala negara.

Sistem presidensial yang dianut oleh UUD NRI 1945 memang seharusnya membentuk posisi yang kuat bagi Presiden sebagai Kepala Pemerintahan, tanpa menafikkan dan mengabaikan peran DPR melalui fungsi pengawasannya. Pengalaman dua orde pemerintahan rezim Soekarno dan Soeharto, sistem presidensial melahirkan executive heavy dimana posisi Presiden sangat kuat sehingga dengan posisi dan otoritasnya yang demikian itu tidak memberikan ruang bagi DPR untuk menjalankan fungsinya sebagai pengimbang dan pengawas (pengontrol) terhadap kebijakan-kebijakan yang diambil oleh Presiden. Pasca era reformasi membawa euforia politik termasuk tuntutan partisipasi masyarakat yang meluas, yang kemudian terwakili oleh banyaknya partai politik. Hal ini mendorong upaya perubahan dengan memperkuat peran DPR melalui amandemen. Sayangnya, perubahan ini tidak secara tuntas menyelesaikan model ketatanegaraan yang akan dibangun. Konstitusi yang telah menguatkan peran DPR (legislative heavy) disatu sisi, ternyata disisi lain tetap mengakui adanya sistem presidensial. Akibatnya dalam praktek sistem pemerintahan presidensial ini menjadi tidak efektif untuk menguatkan kewenangan Presiden, karena setiap keputusan dan kebijakan yang diambil oleh Presiden tidak serta merta atau otomatis dapat dilaksanakan tanpa persetujuan DPR. Faktor lain yang dapat menyebabkan lemahnya posisi dan wewenang Presiden itu, adalah sistem kepartaian dan keberadaan multi partai yang memaksa Presiden harus melakukan koalisi fragmentasi yang sarat dengan kepentingan jangka pendek serta tidak berpihak pada kepentingan rakyat, jika ia 
ingin tetap dapat memperoleh dukungan yang solid dari parpol-parpol tersebut dalam pemerintahannya.

Berdasarkan kondisi tersebut, apabila Presiden ganti maka ganti pula visi misi atau perencanaan pembangunannya. Hal ini berdampak pada perencanaan pembangunan yang menjadi tidak konsisten dan tidak terarah. Oleh karena itu, dibutuhkan sistem perencanaan pembangunan nasional model GBHN. Namun wacana untuk mengembalikan GBHN tidak serta merta produknya seperti GBHN yang lampau yang tidak sesuai dengan sistem presidensial di Indonesia. Model GBHN yang baru, atau yang akan dibentuk nantinya harus mengalami berbagai pembaruan dan sinkronisasi agar sesuai dengan sistem presidensial.

Wacana untuk menghidupkan GBHN kembali diharapkan perencanaaan pembangunan nasional di Indonesia menjadi lebih terarah dan konsisten, karena setiap Presiden pasti membawa visi misi tersendiri. Sehingga kedepannya visi misi yang diusung harus disesuaikan dengan GBHN. Dan nantinya GBHN yang baru, atau apapun namanya nanti, materi di dalamnya tidak boleh bertentangan dengan UUD NRI Tahun 1945. Karena bagaimanapun juga, konstitusi mempunyai kedudukan tertinggi dalam hierarki tata urutan perundang-undangan di negara Indonesia. GBHN yang baru merupakan pedoman yang harus disertai sanksi agar mendapat kekuatan hukum yang tegas sehingga diharapkan akan selalu ditaati oleh para pihak. Karena kita menganut sistem presidensial maka presiden tidak bertanggungjawab kepada parlemen.

Hal yang perlu diperhatikan dalam rangka reformulasi GBHN sebagai sistem perencanaan pembangunan dapat dilakukan diantaranya dengan cara sebagai berikut :

a) Menghidupkan kembali GBHN dapat dilakukan pertama kali dengan mengamandemen UUD NRI Tahun 1945 secara terbatas, yaitu paling utamanya adalah menambah kewenangan MPR di Pasal 3 UUD NRI Tahun 1945 untuk menyusun dan menetapkan GBHN. Mengembalikan kewenangan MPR untuk menetapkan GBHN tidak dalam konteks MPR sebagai lembaga tertinggi negara, melainkan hanya dalam konteks penerapan tujuan negara yang tercantum dalam Pembukaan UUD NRI Tahun 1945 pada alinea keempat. Oleh karena itu, meskipun MPR sudah tidak lagi sebagai lembaga tertinggi negara, tidak menjadi halangan untuk mengembalikan wewenang 
MPR menyusun dan menetapkan GBHN, dimana GBHN itu sendiri merupakan penjabaran dari tujuan negara dalam Pembukaan UUD NRI Tahun 1945.

b) GBHN yang baru akan ditetapkan dengan TAP MPR. Karena lebih menjamin konsistensi pelaksanaan rencana pembangunan dan Pencapaian tujuan negara. Meskipun MPR tetap dalam kedudukannya sebagai lembaga negara, hal ini tidak berati MPR tidak dapat melakukan pengawasan terhadap pelaksanaan GBHN. Pengawasan MPR terhadap pelaksanaan GBHN yaitu dalam pemahaman bahwa GBHN adalah penjabaran dari tujuan negara yang termuat dalam UUD NRI Tahun 1945. Dalam kaitan ini, lembaga-lembaga negara adalah pengemban amanah UUD NRI Tahun 1945, maka pelaksanaan GBHN menjadi keharusan bagi setiap lembaga negara untuk melaksanakannya. Bahkan dalam perspektif presidensial sekalipun, Presiden dalam sumpahnya akan melaksanakan amanah UUD NRI Tahun 1945.

Alternatif model perencanaan pembangunan nasional kedepannya dibagi menjadi dua, yaitu bersifat makro dan mikro:

1) Perencanaan pembangunan bersifat makro atau yang nantinya menjadi haluan negara dibuat untuk jangka waktu yang lama, misal untuk jangka waktu 20tahun, di dalamnya mengatur mengenai pokok-pokok kebijakan pemerintahan yang sifatnya jauh kedepan dan mengikat seluruh lembagalembaga Negara yang ada di Indonesia, termasuk lembaga DPR sebagai pembuat Undang-Undang agar segala produk Undang-Undang yang dibuat arahnya tidak melenceng dari GBHN. Perencanaan makro dibuat dengan produk hukum TAP MPR. Pertimbangannya karena TAP MPR saat ini mempunyai kedudukan langsung dibawah UUD NRI Tahun 1945 dan diatas UU. Yang perlu ditegaskan, walaupun haluan negara atau perencanaan makro ini dibuat oleh lembaga MPR dengan produknya TAP MPR, tetapi hal ini tidak akan mengubah kedudukan MPR menjadi lembaga tertinggi negara seperti di masa UUD Tahun 1945 sebelum perubahan. Hal ini dikarenakan bahwa hierarki norma hukum tidak selalu berkorelasi dengan hierarki organ negara. Karena kalau seperti itu, tentunya sistem presidensial Indonesia menjadi lemah.

2) Perencanaan mikro, di dalamnya berisi pengaturan perencanaan pembangunan untuk jangka menengah (5 tahun) dan jangka pendek 
(tahunan). Tentunya perencanaan mikro inipun tidak boleh bertentangan dengan perencanaan makro.

Sinkronisasi yang kedua adalah, GBHN merupakan manifetasi pemikiran nasional dengan "Bottom Up" tidak boleh seperti dulu yang hanya bersifat "Top Down" yang hanya berisi kebijakan-kebijakan yang bersifat sentralistik. Hal ini dimaksudkan agar kepentingan-kepentingan yang ada di daerah dapat terakomodir. Sehingga nantinya kebijakan nasional dapat sinkron antara pusat dan daerah, karena tidak alasan bagi daerah-daerah tidak menyesuaikan visi misinya dengan pusat. Sebab Negara Kesatuan Republik Indonesia (NKRI) adalah pusatnya daerah, dan daerah adalah pusatnya pemerintahan otonomi daerah. Demi terwujudnya hal ini, maka perlu diadakan pertemuan antara pusat dan daerah yang diwakili oleh Presiden dan Kepala Daerah di seluruh Indonesia, lembaga-lembaga negara, serta para akademisi untuk mengakomodir pembuatan GBHN model baru nanti agar sesuai dengan semangat otonomi daerah yang kita usung.

Apabila nanti GBHN baru model presidensial ini dihidupkan kembali sebagai dokumen perencanaan pembangunan jangka panjang, maka keberadaan SPPN dalam UUNomor 25 Tahun 2004 perlu ditinjau ulang, untuk setidaknya mengubah beberapa hal, diantaranya :

a) menghapus keberadaan RPJPN agar tidak bertabrakan dengan GBHN atau haluan negara yang baru.

b) Ketentuan RPJPMN perlu ditata ulang, misalnya dengan menempatkannya dalam bentuk Undang-Undang yang berkorelasi dengan merencanakan anggaran, agar DPR dapat melakukan fungsi pengawasannya menjadi lebih efektif.

Upaya memunculkan kembali GBHN dalam sistem presidensial di Indonesia, jangan sampai hanya menimbulkan kesan mengganti nama saja dari RPJPN ke GBHN model yang baru. Dengan bentuk TAP MPR, GBHN yang baru akan menjadi alat kendali untuk mengukur tingkat keberhasilan dan ketepatan perencanaan pembangunan jangka menengah (RPJPMN) yang diberi bentuk dalam produk Undang-Undang.TAP MPR secara teoritik merupakan staatsgerundgezets (aturan dasar bernegara), sama seperti Undang-Undang, namun kedudukannya setingkat dibawah UUD NRI Tahun 1945 (Hamid S. Attamimi, 1990). Artinya, masyarakat dapat menilai nantinya apakah RPJPMN 
yang dibuat nantinya bertentangan dengan GBHN atau tidak, dengan melalui uji materiil.

\section{PENUTUP}

Reformulasi perencanan pembangunan nasional yang tepat saat ini adalah mengembalikan kembali GBHN. Wacana menghidupkan kembali GBHN oleh MPR semata-mata hanya untuk memberikan pedoman pembangunan nasional agar menjadi lebih terarah dan konsisten, namun tetap berpegang teguh pada kerangka sistem presidensial di Indonesia.Artinya, bagaimanapun nanti kedudukan GBHN yang baru, tidak menimbulkan pengaruh terhadap kedudukan MPR menjadi lembaga tertinggi negara seperti di masa UUD Tahun 1945 sebelum perubahan, dan tidak mempengaruhi pertanggungjawaban politik Presiden dan Wakil Presiden kepada MPR. Hal ini dikarenakan bahwa hierarki norma hukum tidak selalu berkorelasi dengan hierarki organ negara. Karena kalau seperti itu, tentunya sistem presidensial Indonesia menjadi lemah. Dengan TAP MPR yang berkedudukan di atas UU, GBHN yang baru nanti harus menjadi acuan dalam pembentukan dokumen perencanaan pembangunan dibawahnya.

\section{DAFTAR PUSTAKA}

Attamimi S, Hamid. 1990. Peranan Keputusan Presiden Republik Indonesia Dalam Penyelenggaraan Pemerintahan Negara. Disertasi Fakultas Pasca Sarjana.

Hamidi, Jazim dan Mustafa Lutfi. 2010. Civic Education : Antara Realitas Politik dan Implementasi Hukumnya. Jakarta : Gramedia Pustaka Utama.

Hasbi Arbi, Muhammad. "UUD-1945 dan GBHN Sebagai Kendali Yuridis Dalam Pembangunan Nasional” Variasi : Vol. 4 No.12, Juni-Juli 2013.

Huda, Ni'Matul. 2007. Lembaga Negara dalam Masa Transisi Demokrasi. Yogyakarta : UII Press.

Rahmatunnisa, Mudiyati. Sistem Perencanaan Pembangunan Nasional, Garis-Garis Besar aluan Negara dan Peran MPR, makalah disampaikan pada Seminar Nasional Ketatanegaraan Indonesia : Reformulasi Model GBHN: Tinjauan Terhadap Peran dan Fungsi MPR RI dalam Sistem Perencanaan Pembangunan Nasional, Kerjasama MPR dengan Universitas Padjadjaran, Hotel Aston Tropicana Cihampelas, Kamis 25 April 2013.

Simamora, Janpatar. Urgensi Keberadaan GBHN Dalam Sistem Ketatanegaraan Republik Indonesia. Litigasi, Vol. 17(2), 2016. 
Undang-Undang Tentang Sistem Perencanaan Pembangunan Nasional. UU No. 25 Tahun 2004. LN No.104 Tahun 2004, TLN No.4421. 